\section{Effects of Onion (Allium cepa) and Lemongrass (Cymbopogon citratus) Extracts on Lipid Oxidation and Acceptability of Frozen Deboned Milkfish (Chanos chanos)}

Karen Grissel M. Ordialez ${ }^{1}$, Ma. Cecelia Esperanza Braceros-Agbon ${ }^{1}$, Gaily Jubie Hontiveros ${ }^{1}$ and Concepcion N. Portugal $^{2}$

${ }^{1}$ Department of Fish Processing and Marine Biology, Mindanao State University-General Santos City, Philippines

${ }^{2}$ Department Aquaculture, Mindanao State University-General Santos City, Philippines

"Corresponding author: Karen Grissel M. Ordialez, Department of Fish Processing and Marine Biology, Mindanao State University-General Santos City, 9500, Philippines, E-mail: grissel.ordialez@gmail.com

Received date: November 5, 2015; Accepted date: June 12, 2016; Published date: June 30, 2016

Copyright: (c) 2016 Ordialez KGM, et al. This is an open-access article distributed under the terms of the Creative Commons Attribution License, which permits unrestricted use, distribution, and reproduction in any medium, provided the original author and source are credited.

\begin{abstract}
This study was conducted to determine the effectiveness of red onion (Allium cepa) and lemongrass (Cymbopogon citratus) extracts on lipid oxidation and on its effect on acceptability of frozen deboned milkfish (Chanos chanos). The deboned milkfish fillets were immersed in $5 \%(\mathrm{v} / \mathrm{v})$ aqueous solutios of onion and lemongrass extracts including the Vitamin $\mathrm{C}$ and stored up to 30 days in frozen storage $\left(18^{\circ} \mathrm{C}\right)$. Chemical indices of lipid oxidation were analyzed by Peroxide Value Determination, $\mathrm{pH}$ and Free Fatty Acid Determination. Changes in the organoleptic properties particularly flavor, color and odor were also determined using a Sensory Descriptive Score sheet and General Acceptability was likewise assessed using a 5-point hedonic scale.
\end{abstract}

Results of the study showed that among the treatments, onion extract-treated samples exhibited a significant decrease in Peroxide Value at $R=0.941$ with a final Peroxide Value of $0.75 \mathrm{meq} / \mathrm{kg}$ sample which did not exceed the USFDA standard at 7-8 meq/kg, not exceeding to $20 \mathrm{meq} / \mathrm{kg}$ and not more than $\leq 5.0 \mathrm{meq} / \mathrm{kg}$ sample.

No significant difference, however, were observed in Free Fatty Acid Value between treatments throughout the 30-day study period which denotes that the extracts have no effect on lipid hydrolysis brought about by lipolytic activity enzyme.

Sensory evaluation revealed that among the treatments the lemongrass extract treated samples yielded the highest general acceptability scores within the 30-day storage period. Statistical analysis however reveals that there is no significant difference between treatments at $5 \%$ level of significance.

Keywords: Peroxide value; Free fatty acid; Lipid oxidation; Acceptability; Sensory

\section{Introduction}

Due to its abundance in the Philippine waters and its tasty flesh, Milkfish (Chanos chanos) is considered as the National Fish. Milkfish is widely cultivated in brackishwater, freshwater and marine waters. Due to its negative attribute of having so many bones in the flesh, deboning is one of the processes to increase its acceptability in the market. Deboned milkfish can be further processed into smoked, canned, and fermented products to prolong its shelf-life.

Fresh fish is a highly perishable product due to its biochemical properties [1]. Fish spoils faster because spoilage begins soon after death. These processes result in autolysis [2]. Fish flesh contains depot of fats that comprises of many fatty acids with five to six double bonds [3]. Fish fat is rich in polyunsaturated fatty-acid, the so-called omega-3.

Lipid oxidation is a major cause of quality deterioration in food muscles [4] as it produces sour flavor that occurs during manufacturing, storage, distribution and final preparation of foods. Lipid oxidation products are abundant in foods, much variation exists in their kind and levels present. Although levels of these compounds are generally low, the problem of lipid oxidation severely compromises the quality of some food products and limits the shelf-life of others [5].

One of the strategies to reduce oxidation and prevention of the quality loss and sensory attributes is the incorporation of antioxidants [6]. Consequently, there has been a growing interest of using natural antioxidant substances to replace the synthetic additives such as, butylated hydroxytoluene (BHT), butylated hydroxyanisole (BHA) and tert-butylhydroquinone (TBHQ), are highly carcinogenic [7] and thereafter rejected by the consumers. Natural antioxidants have a considerable role as functional and biochemical inhibitors of oxidative damage induced by free radicals. Many plant tissues are good source of phytochemicals, particularly phenolic compounds and flavonoids [8] that can act as the best alternative to these carcinogenic additives.

This study aims to look for natural antioxidants from locally available plants. The effect of red onion (Allium cepa) and lemongrass (Cymbopogon citratus) on lipid oxidation and acceptability of deboned Milkfish (chanos chanos) were assessed. Chemical parameters namely peroxide value; free fatty acid value and $\mathrm{pH}$ were monitored during the 30-day period of frozen storage. Changes in the organoleptic characteristics were likewise determined. 
Citation: Ordialez KGM, Braceros-Agbon MCE, Hontiveros GJ, Portugal CN (2016) Effects of Onion (Allium cepa) and Lemongrass (Cymbopogon citratus) Extracts on Lipid Oxidation and Acceptability of Frozen Deboned Milkfish (Chanos chanos). J Exp Food Chem

\section{Materials and Methods}

\section{Raw materials}

One hundred sixty (160) pieces of fresh milkfish (Chanos chanos) with an approximate weight of 200-250 grams were purchased from Malalag Bay Aquaculture and Processing Corporation. Samples were chilled and backbone temperature (BBT) maintained at $0^{\circ} \mathrm{C}$ to $3^{\circ} \mathrm{C}$ in styropore boxes during transportation to the Fish Processing Laboratory of College of Fisheries, Mindanao State University-General Santos City. Samples were then eviscerated, filleted, deboned and placed in zip lock bags and frozen.

\section{Plant sample collection and extract preparation}

Fresh red onions (Allium cepa) were purchased from the General Santos City Public Market. Bulbs were skinned prior to the extraction. The flesh part was used in the extraction. Fresh lemongrass was obtained from Brgy. Glamang, General Santos City.

Two (2) kilograms of red onions (Allium cepa) was finely chopped and homogenized with $60 \mathrm{ml}$ of distilled water in a blender for 2 minutes. The homogenate was filter-pressed using cheesecloth to obtain the crude extract [9].

Lemongrass leaves and stalks were chopped finely and homogenized with $30 \mathrm{ml}$ of distilled water in a blender for 5 minutes. The homogenate was filter-pressed using cheesecloth to obtain the crude extract.

Milkfish (Chanos chanos) was deboned following the standard methods [10]. The fins were trimmed. Removal of fins and other nuisance bones were done by making a small cut around the base of the large fins, and then it will be pulled forward. The fish was divided down from the dorsal side and it will be laid open like a butterfly fillet; removing of the gills and internal organs. Removal of the backbone was done by holding the knife horizontally and cut the backbone. With the aid of forceps, the rib bones, the bones of the dorsal, the ventral side and the lateral line which includes the filamentous $y$-shaped spines are removed. During deboning, the fish were sufficiently iced to cool it down.

\section{Incorporation of antioxidant extracts}

An aqueous solution of each plant extract and the positive control of Vitamin C diluted in distilled water at the concentration of $5 \%(\mathrm{v} / \mathrm{v})$ were used. Deboned milkfish (Chanos chanos) were immersed in the three treatment solution $(\mathrm{T} 2, \mathrm{~T} 3, \mathrm{~T} 4)$ in $1: 1$ ratio $(\mathrm{w} / \mathrm{v})$ with three replicates [11]. After immersing, the fish samples were drained for 5 minutes and packed in the zip lock bag and stored in a freezer for 30 days.

Treatments were placed in frozen storage for 30 days. Samples were collected at Day 0 for analysis and succeeding samplings for the analysis of lipid oxidation indices and sensory characteristics were done every six days.

\section{Peroxide value determination}

The peroxide value determination was done following the standard methods [12]. Briefly, $5.00 \pm 0.05 \mathrm{~g}$ of sample was weighed in $250 \mathrm{ml}$ stoppered Erlenmeyer flask and the weight was recorded to the nearest $0.1 \mathrm{~g}$. $30 \mathrm{ml}$ of acetic acid-chloroform solution was added then the flask was swirled until the sample was completely dissolved. Using $1 \mathrm{ml}$
Mohr pipette, $0.5 \mathrm{ml}$ of saturated potassium iodide solution was added. The flask was stoppered and the contents were swirled for one minute. Immediately $30 \mathrm{ml}$ of distilled water was added to the solution. The flask was again stoppered then shook vigorously to liberate the iodine from chloroform layer.

Fill the burette with $0.1 \mathrm{~N}$ sodium thiosulfate. If the starting color of the solution was deep red orange, titrate slowly with mixing until the color lightens. If the solution was initially a light amber color, go to the next step. Using a dispensing device, $1 \mathrm{ml}$ of starch solution was added as indicator. Titrate until the blue-gray color disappears in the aqueous (upper) layer. Accurately record the volume of titrant.

Peroxide Value $=\frac{(S-B) \times N \text { thiosulfate } \times 1000}{\text { Weight of the Sample }}$

Or

Peroxide Value $=(S-B) \times N$ thiosulfate $\times 200$

Where:

$\mathrm{S}=$ Titration of the Sample (volume used with the incorporation of the sample)

$\mathrm{B}=$ Titration of Blank (volume of the blank titration; indicator)

\section{Free-fatty acid determination}

The Free-Fatty Acid Determination was done following the standard methods [13]. Sample was weighed to 0.1 gram accuracy into a $250 \mathrm{ml}$ Erlenmeyer flask. $50 \mathrm{ml}$ neutralized isopropanol was added to the weighed sample. 5 drops of phenolphthalein solution was added as an indicator and titrated with standardized $0.5 \mathrm{~N}$ potassium hydroxide to a pink endpoint.

$$
\begin{aligned}
& \text { Acid Value }=\frac{m L K O H \times N \times 56.1}{\text { Weight of sample in grams }} \\
& \text { Free }- \text { Fatty Acid } \%=\frac{m L K O H \times N \times M W(\text { fatty acid })}{10 \times \text { weight of sample in grams }}
\end{aligned}
$$

Where:

$56.1=$ millivalue of $\mathrm{KOH}$

MW=molecular weight

\section{pH Determination}

The $\mathrm{pH}$ was measured using a $\mathrm{PH}-80$ digital $\mathrm{pH}$ meter at room temperature on homogenates in distilled water at a ratio of $1: 10(\mathrm{v} / \mathrm{v})$ [14].

\section{Sensory evaluation}

Fillets of fish samples were wrapped in aluminum foil and steamed for 20 minutes. Fish samples were coded for randomization and to avoid bias. A panel of 10 assessors evaluated the taste, color and odor of the samples on a 7-point hedonic scale using a sensory score sheet (Appendix 1) patterned after Gatchalian (1971).

\section{Statistical analysis}

Results of chemical analysis (peroxide value, free-fatty and $\mathrm{pH}$ ) were subjected to Linear Regression and sensory data were subjected to one way ANOVA at $\alpha=0.05$ and Duncan's Multiple Range Test (DMRT) with 5\% level of significance were performed as a post-hoc test to compare means of significantly different treatments. Statistical 
Citation: Ordialez KGM, Braceros-Agbon MCE, Hontiveros GJ, Portugal CN (2016) Effects of Onion (Allium cepa) and Lemongrass (Cymbopogon citratus) Extracts on Lipid Oxidation and Acceptability of Frozen Deboned Milkfish (Chanos chanos). J Exp Food Chem

Page 3 of 5

analyses were done using SPSS for windows version 20. Data were presented as means \pm standard deviation.

\section{Results and Discussion}

\section{Changes in peroxide value (PV)}

The effects of onion extract (OE) and lemongrass extract (LGE) on the changes in the Peroxide Value (PV) of the deboned milkfish (Chanos chanos) during the 30 days of frozen storage are shown in Figure 1.

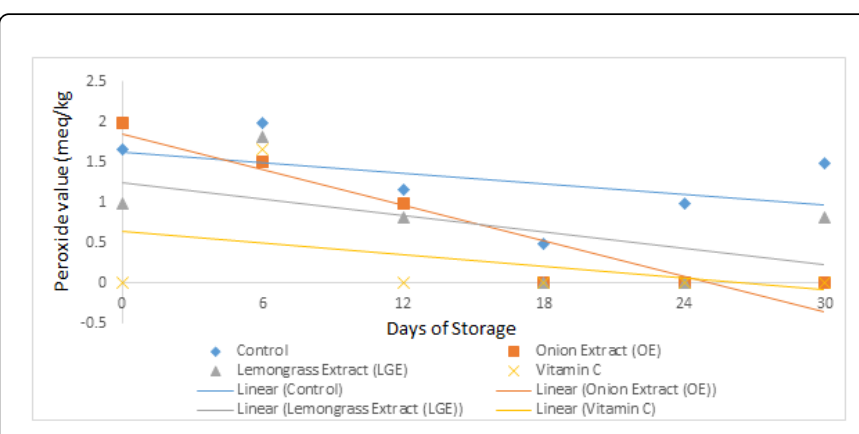

Figure 1: Effect of onion (OE), lemongrass Extract (LGE) on Peroxide Value of deboned milkfish from 0 to 30 days of frozen storage.

The final peroxide value of the untreated samples (Control) is $2.04 \pm$ $1.47 \mathrm{meq} / \mathrm{kg}$ which is generally high compared to the three treatments. The positive control (Vitamin C) yielded for the lowest peroxide value. Onion extract (OE) had a peroxide value of (PV) $0.75 \pm 0.877 \mathrm{meq} / \mathrm{kg}$ sample, Lemongrass Extract (LGE) with $0.74 \pm 0.684 \mathrm{meq} / \mathrm{kg}$ sample and Vitamin C with $0.28 \pm 0.677 \mathrm{meq} / \mathrm{kg}$ sample, respectively.

Peroxide value $(\mathrm{PV})$ measures the concentration of peroxides and hydroperoxides formed in the initial stages of lipid oxidation and it is widely used for the estimation of oxidative rancidity in fats and oils [15].

Based on the results, the untreated sample (Control) is more prone to oxidative rancidity development than the treated samples.

Linear regression analysis revealed that the onion extract-treated samples exhibited a significant decrease in Peroxide Value at $\mathrm{R}=0.941$ and a slope of -0.07352 with a final Peroxide Value of $0.75 \mathrm{meq} / \mathrm{kg}$ sample which did not exceed the USFDA standard. Peroxide value's acceptability limit in fish oil is $7-8 \mathrm{meq} / \mathrm{kg}$, not exceeding to $20 \mathrm{meq} / \mathrm{kg}$ and not more than $\leq 5.0 \mathrm{meq} / \mathrm{kg}$ as maximum level for fish products (US-FDA, CFR).

Analysis of Variance (ANOVA) also revealed that there is a significant difference among treatments $(\mathrm{p}<0.05)$ at day 30 . This result was in agreement with the study conducted by Hadiseh [11] when the antioxidative property of onion was evaluated in sturgeon fish. A slower increase in PV values was obtained in samples treated with onion extract (OE), in contrast to a faster increase in PV of the control sample after 2 days of refrigerated storage time, demonstrating the oxidative stability of fish lipids by onion extract.
The fish oil extracted from all deboned milkfish samples stored in frozen storage $\left(-18^{\circ} \mathrm{C}\right)$ did not exceed limit for the peroxide value throughout the 30-day frozen storage.

\section{Changes in free fatty acid}

Progressive oxidation and enzymatic hydrolysis of unsaturated fatty acids is the main cause of lipid deterioration in fatty fish which is accompanied by the formation of free fatty acids [16]. The Free Fatty Acid (FFA) values of the lipid extracted from the four treatments is shown on Figure 2.

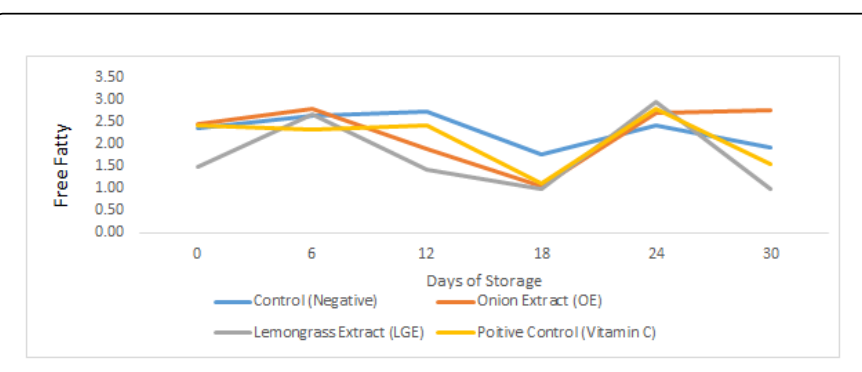

Figure 2: Effect of onion extract (OE), lemongrass extract (LGE) levels on the Free Fatty Acid in deboned milkfish from 0 to 30 days of frozen storage $\left(-18^{\circ} \mathrm{C}\right)$.

In day 0 , the FFA values for the four treatments were recorded to range between $0.98 \%$ and $2.95 \%$. Statistical analysis revealed that there is no significant differences $(p>0.05)$ among treatments on the Free Fatty Acid values in fish oil extracted in deboned milkfish (Chanos chanos) Day 0 to Day 24.

Linear regression analysis revealed that there is no significant increase or decrease in all the treatments in Free Fatty Acid Value which denotes that the inhibitory effects of the phenolic compounds in the lipid hydrolysis may due to lipid hydrolyzing enzymes (mainly lipase and phospholipase) in decomposing the fats of fish tissue (phospholipids and triglycerides) during the first stages of refrigerated storage [6].

For the 30th day of frozen storage Analysis of Variance (ANOVA) revealed that the four treatments have significant differences among each other. Therefore, Onions contain quercetin, a flavonoid (one category of antioxidant compounds), different inhibitory effects of phenolic compounds on lipid hydrolysis on frozen deboned milkfish (Chanos chanos) could be implied [11].

\section{Changes in $\mathrm{pH}$}

Changes in $\mathrm{pH}$ value of deboned milkfish dipped in antioxidant solutions and the control are shown during 30-day frozen storage in Figure 4. Assessed as a crucial factor for determination of meat quality is the $\mathrm{pH}$ [17]. As the $\mathrm{pH}$ drops, the net surface charge on the muscle proteins is reduced, causing them to partially denature and lose some of their water-holding capacity (FAO).

In this study, the $\mathrm{pH}$ value of four treatments ranged between 4.97 and 6.23. Initially, the $\mathrm{pH}$ was between 5 and 5.9 then increased at day 6. At Day 12, Day 24 and Day 30, the $\mathrm{pH}$ value of the deboned milkfish decreased at the same level. The increase in $\mathrm{pH}$ was said to be due to 
Citation: Ordialez KGM, Braceros-Agbon MCE, Hontiveros GJ, Portugal CN (2016) Effects of Onion (Allium cepa) and Lemongrass (Cymbopogon citratus) Extracts on Lipid Oxidation and Acceptability of Frozen Deboned Milkfish (Chanos chanos). J Exp Food Chem

Page 4 of 5

an increase in volatile bases compounds produced by either endogenous or microbial enzymes (Figure 3).

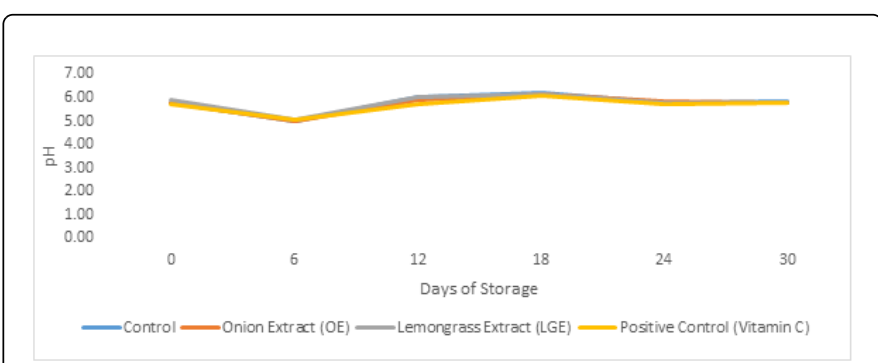

Figure 3: Effect of onion extract (OE), lemongrass extract (LGE) levels on the $\mathrm{pH}$ in deboned milkfish from 0 to 30 days of frozen storage $\left(-18^{\circ} \mathrm{C}\right)$.

Linear regression analysis and analysis of variance revealed that there is no significant difference at $5 \%$ level of significance $(\mathrm{p}>0.05)$ among the treatments throughout the 30 -day frozen storage period.

\section{Sensory analysis}

The deboned milkfish was evaluated in color, odor, taste and the overall general acceptability for 30 days. Analysis of variance (ANOVA) was used to determine the significant differences between means. Sensory acceptability test were based on a 7-point hedonic scale with the limit score of 4.0, higher than 4.0 means that the product is not acceptable to the panelists.

The following are graphical representations of each sensory attributes namely taste, color, odor and the general acceptability.

To sum up, in taste liking, the lemongrass extract (LGE) obtained the least mean score at day 30 and developed a taste similar to the milkfish that is cooked as sinigang. In color liking, the three treatments (onion-treated, lemongrass treated extract and control) are acceptable according to the acceptable limit while the Vitamin C-treated extract, not acceptable due to discoloration. In odor liking, the scores reached the acceptable limit.

\section{Taste}

Figure 4 shows the changes in taste mean scores of the deboned milkfish (Chanos chanos) during the 30-day frozen storage.

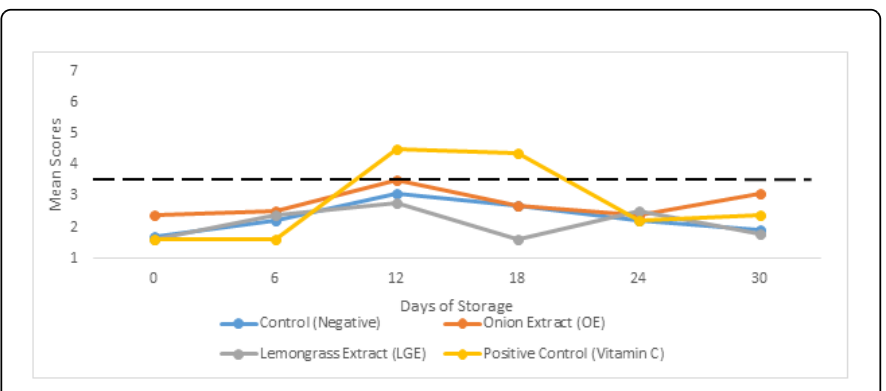

Figure 4: Taste Scores of Deboned Milkfish (Chanos chanos) stored in freezing temperature.

A mean score of $1.7 \pm 0.48$ (Control), $2.4 \pm 0.84(\mathrm{OE}), 1.6 \pm 0.97$ (LGE) and $1.6 \pm 0.84$ (Vitamin C) respectively in the initial stage of sensory evaluation (Day 0). During the 12th day and the 18th day of storage, the Vitamin $\mathrm{C}$, tended to increase reached the acceptability limit and decreases in the 24th day. This is due its sour flavor and its $\mathrm{pH}$ at day 12 and day 18. A slight decrease or increase in $\mathrm{pH}$ affects the chemical components of the fish. In this study, the sour flavor that occurs at the Days 12 and 18 is due to its $\mathrm{pH}$ and the formation of Lactic Acid Bacteria and protein denaturation.

There is no significant difference in taste during Day 0 , day 6 , and day 24 between treatments. There is a significant difference $(\mathrm{p}<0.05)$ during day 12 , day 18 and day 30 . At day 30, the onion extract (OE) has the highest mean score among treatments developed off-taste. The lemongrass extract (LGE) obtained the least mean score at day 30 and developed a taste similar to the milkfish that is cooked as sinigang. This taste develops due to the property of lemongrass as aromatic flavor and odor enhancer.

\section{Color}

Figure 5 shows the color mean scores of deboned milkfish immersed in Onion Extract (OE), Lemongrass Extract (LGE) and Vitamin C. At the initial stage of sensory evaluation, the deboned milkfish obtained 1.4 (Control), 2.1 (OE), 1.6 (LGE) and 2 (Vitamin C) respectively. Mean scores of the treatments tend to increase on day 6 with ratings of 2.5 (Control), 2.2 (OE), 1.9 (LGE) and 2.3 (Vitamin C).

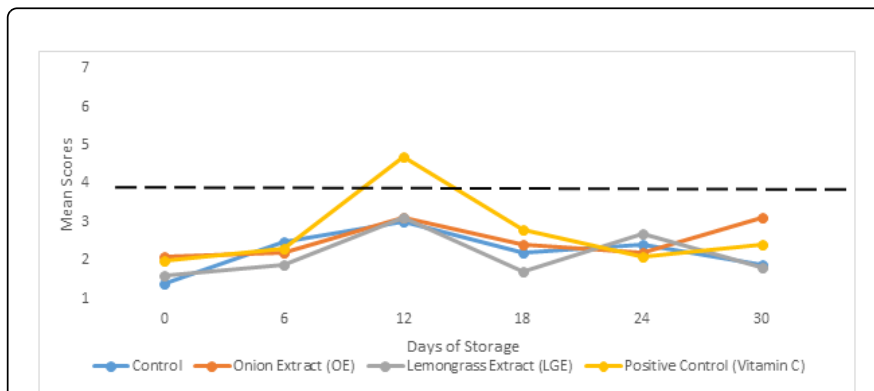

Figure 5: Color scores of Deboned Milkfish Chanos chanos) stored in freezing temperature.

At day 12, the mean score of Vitamin C increases to 4.7, which means the product, is not acceptable because it is higher than the acceptable limit which is 4.5 . It was due to yellow discoloration of the fish flesh.

There was a significant difference between the scores in day 18 and day 24 at $0.05 \%$ level $(\mathrm{p}<0.05)$ among the treatments which means that the Vitamin $\mathrm{C}$ on the 18th and 24th day having yellow discoloration color. The discoloration develops due to the color of the Vitamin C which is yellow.

\section{Odor}

Figure 6 shows the odor means scores of deboned milkfish during 30 -day frozen storage. At the initial stage of the sensory evaluation, the deboned milkfish obtained the mean of score 1.7 (Control), 2.4 (OE), 1.6 (LGE) and 1.6 (Vitamin C), respectively.

At the initial stage of the sensory evaluation, the deboned milkfish obtained the mean scores of 1.4 (Control), 2.2 (OE), 1.5 (LGE) and 1.9 (Vitamin C). On the day 6, there is a slight decrease. An increase of the odor mean scores was obtained on the 12th day and the scores are 
Citation: Ordialez KGM, Braceros-Agbon MCE, Hontiveros GJ, Portugal CN (2016) Effects of Onion (Allium cepa) and Lemongrass (Cymbopogon citratus) Extracts on Lipid Oxidation and Acceptability of Frozen Deboned Milkfish (Chanos chanos). J Exp Food Chem

Page 5 of 5

above the acceptable limit. A decrease on the 18th and 24th day. An increase on the 30th day.

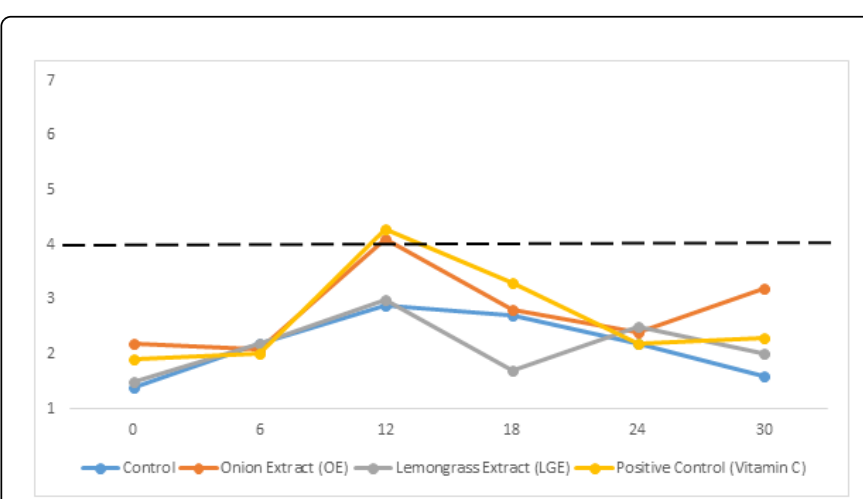

Figure 6: Odor mean scores of deboned milkfish.

Untreated sample and Vitamin C have significant difference between and among treatments on day 12 , day 18 and day 30 .

\section{General acceptability}

General acceptability mean scores of deboned milkfish during 30day frozen storage are presented in Figure 7. An average score of 2.5 was the acceptable limit. Lower than 2.5 are not acceptable.

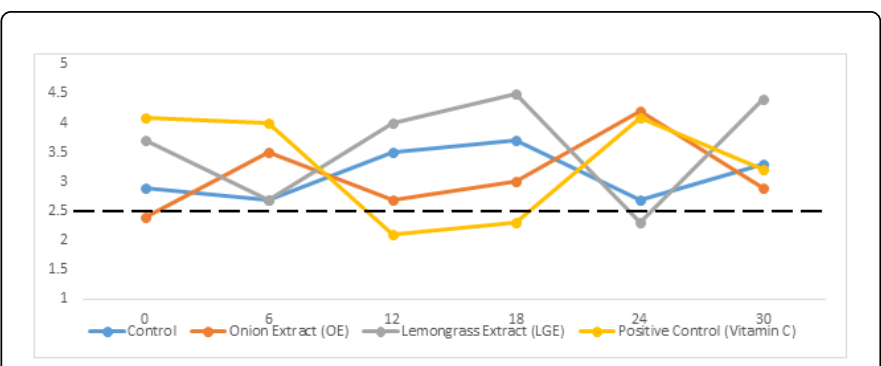

Figure 7: General Acceptability scores of the deboned milkfish.

Using significance level of $0.05 \%$, results showed that there was a significant difference in the general acceptability among the treatments.

\section{Conclusion and Recommendation}

Results of this study revealed that frozen deboned milkfish treated with onion (OE) extract generally had lower peroxide value and free fatty acid values than the control. There is a uniform $\mathrm{pH}$ throughout the study. On the other hand, lemongrass (LGE) extract treated samples exhibit the highest general acceptability score.

Statistical analysis revealed that there's no significant difference between onion and lemongrass extract. Even though the onion-extract treated samples has lower peroxide value but it is not acceptable than the lemongrass extract treated sample, based on the results, the lemongrass extract-treated samples is the best to inhibit lipid oxidation and it is acceptable.
It is likewise recommended that methanol-chloroform method of lipid extraction developed by Bligh and Dyer and Soxhlet method of lipid extraction method must be used to obtain the lipids. The study must undergo thiobarbituric reactive substance (TBARS) test to further determine the advanced rancidity during a longer storage study.

\section{References}

1. Corbo MK, Speranza B, Filippore A, Granaterio S, Sinigaglia M, et al (2008) Study on the synergic effect of natural compounds on the microbiological quality of decay of packed fish hamburger. Int J Food Microbiol 127: 261-267.

2. Hermes-Espejo (1998) Fish Processing in the Tropics. Tawid Publications, Quezon City, Philippines p 336.

3. Standsby ME, Hall AS (1967) Chemical Composition of Commercially Important Fish of the USA. Fish Ind Res 3: 29-34.

4. Ladikose D, Lougovoise V (1990) Lipid Oxidation in Muscle Food: A review: Food Chemistry 35: 295-314.

5. Wasowicz E, Gramza A, Heoe M, Jelen HH, Korczak J, et al. (2004) Oxidation of Lipids in Food. Pol J Food and Nutr Sci 54: 87-100.

6. Serdarglu M, Felekoglu E (2005) Effects of using rosemary extract and onion juice on oxidative stability of sardine (Sardina pilchardus) mince. Journal of Food Quality 28: 109-120.

7. Pereitti P, Gai F, Ortoffi M, Aigotti R, Medana C (2012) Effects of Rosemary oil (Rosemarinus officinalis) on the Shelf-life of Minced Rainbow Trout (Oncorhynchus mykiss) during refrigerated storage. Foods 1: 28-39.

8. Gorinstein S, Drzewiecki J, Leontowicz H, Leontowicz M, Najman K, et al. (2005) Comparison of the Bioactive compounds and antioxidant potentials of fresh and cooked Polis, Ukrainian and Israeli garlic. J Agric Food Chem 53: 2726-2732.

9. Guinares RC, Agbon MCEB, Campeon AS, Belinario MFM (2014) Effects of Garlic (Allium sativum) Extract on Lipid Oxidation, Microbiological and Organoleptic Qualities in hot-Smoked Sardines (Sardinella longiceps) During Frozen Storage. International Journal of Fisheries and Aquatic Studies 1: 87-94.

10. BFAR-7 (2001) Central Visayas Technology Guide on Post-harvest Technology. Bureau of Fisheries and Aquatic Resources Region VII (BFAR-7).

11. Hadiseh S, Gholamhosser A, Bahareh S (2010) Effect of Green tea (Camellia sinensis) extract and onion (Allium cepa) on Lipid Degadation and Sensory Acceptance of Persian Sturgeon (Acipenser persicus) Fillets. International Food Research Journal 17: 751-761.

12. American Oil Chemists' Society (AOCS) (1995) Official Methods of Analysis. Association of Official Analytical Chemists, Washington, DC p 200.

13. Acid Value AOCS Society (1998) Cd 3a-63. Official Methods and Recommended Practices. Ed 5, (Peroxide Value Acetic Acid- Isooctane Method).

14. Association of Analytical Chemists (AOAC) (1990) Official Methods of Analysis, Association of Official Analytical Chemists, 15th edition, Washington, DC pp 951-952.

15. Ólafsdóttir G, Martinsdo' ttir E, Oehlenschla“ger J, Dalgaard P, Jensen B, et al. (1997) Methods to evaluate fish freshness in research and industry. Trends in Food Science and Technology 8: 258-265.

16. Srikar LN, Hiremath JG (1972) Fish preservation-1. Studies on changes during frozen storage of oil sardine. Journal of Food Science and Technology 9: 191-193.

17. Nam KC, Ahn DU, Du M, Je C (2001) Lipid oxidation, colour, volatiles, and sensory characteristics of aerobically packaged and irradiated pork with different ultimate. Journal of Food Science 66: 1225-1229. 